\title{
PHYSIOLOGICAL PROBLEMS OF MINING
}

$\mathrm{O}^{2}$ $\mathrm{N}$ August 9, at the recent meeting of the British Association in Edinburgh, Section I (Physiology) devoted a whole morning session to a number of papers and discussion on "Physiological Problems of Mining". Dr. G. C. Gooding (Scottish Coal Board, Edinhurgh), in his review of the "Effects of Lighting on the Health and Working Efficiency of Miners", said that the development of adequate mine lighting in Great Britain has been hindered by the presence of firedamp. The evolution of the miner's lamp has been slow : the electric cap lamp was a big advance, and, although this is the commonest lamp in use to-day, in many districts other less-efficient lamps have not been replaced. Fixed lighting was first used at a shaft bottom in 1881 and is slowly extending. Installations of fluotescent lighting both at the shaft bottom and the coal face have been tried in the past five years and given promising results. Only a fraction of the light produced is reflected from the coal face and this impairs the illumination.

Miner's nystagmus is a disease, which may be incapacitating, associated with inadequate lighting. This disease is now much less common than it was thirty years ago, yet it has disabled for periods of one or more years more than fourteen thousand miners in the derade 1938-47. In some parts, Scotland for example, the disease appears to be checked though not abolished entirely. Continual caution is necessary, since the disease may exist in latent form, which may be converted to overt disability in adverse social circumstances.

With the best lighting available it is now possible to control miner's nystagmus; but good lighting is much more than prophylactic against this disease. Other benefits arising from improvements in lighting in mines are increased output and increased safety. Some small-scale trials have demonstrated both a reduction of accidents and the production of cleaner coal following improvements in lighting. The benefit which is probably the most important is an improvement in physical comfort and psychological temper. An improvement in lighting, sufficient to convert mines into underground factories, would work a revolution in the psychological climate in the industry. Increased comfort is a legitimate aim, being closely associated with industrial efficiency. The miner's job has been described as dirty, dangerous and dark. Attempts have been made, with at least partial success, to mitigate the dirt and reduce the danger. It is a legitimate aspiration for the industry to attempt to remove the dark, and with it another edge cf asperity in the miner's life.

The next speaker, Dr. C. M. Fletcher (Medical Research Council Pneumoconiosis Unit, South Wales), discussed the "Effect of Dust Inhalation on the Working Capacity of Miners". Since statistics have been available, coal-miners (and especially elderly miners) have always been shown to suffer from a relatively high mortality from respiratory diseases other than tuberculosis and a relatively low mortality from pulmonary tuberculosis. This relative freedom from tuberculosis was ascribed by $J$. S. Haldane to a possible beneficial effect of coal-dust. Modern studies have confirmed that the inhalation of coaldust modifies the effects of pulmonary tuberculosis and that in some ways this may be beneficial. Yet the serious effect of the inhalation of coal-dust on miners' working capacity has become increasingly apparent, especially as the result of admission of miners to compensation under the provision of the Workmen's Compensation Acts for silicosis, in the first place, and now for pneumoconiosis. The prevalence of pneumoconiosis has been very much greater in South Wales than in the other coal-fields, and the reason for this is not certain.

Pathological studies have shown that dust accumulates in and around the bronchioles where there is a minimal reticulin reaction to its presence. At this stage, simple pneumoconiosis, the dust could not be expected to cause any important disturbance of respiratory function. In elderly coal-workers the lung tissue in the neighbourhood of the deposit of coal-dust may become broken down to form 'focal emphysema'. If there are no complications, this focal emphysema is only occasionally so severe as to interfere with respiratory function. In some cases of coal-worker's pneumoconiosis, collagenous fibrosis occurs in the deposits of coal dust. Collagenous nodules of irregular shape form and later coalesce to form large areas of massive fibrosis which may seriously distort the lung and interfere seriously with its function, and in addition impose a strain on the pulmonary circulation.

Radiological studies enable a distinction to be made in life between simple pneumoconiosis and massive fibrosis, and a system of radiological classification has been developed. A correlation has been worked out between the radiological findings and a test of respiratory efficiency, and from this it is concluded that serious disability in coal-worker's pneumoconiosis is chiefly due to the presence of massive fibrosis.

"Coalminer's Pneumoconiosis : Employment Problems of the Disabled" was the subject of a paper by Dr. A. Meiklejohn (University of Glasgow). While hitherto the main incidence of certified pneumoconiosis has been in South Wales, there is evidence that, for various reasons, the number is increasing in other mining areas. It is not possible to provide satisfactory alternative jobs for these disabled miners. Reluctantly the conclusion has been reached that almost the entire responsibility for the continued employment of pneumoconiotic coal-miners must be accepted by and within the industry. The problem is not rehabilitation of disabled coal-miners, but rehabilitation of unfit coal-mines. In this assignment the main burden must fall on the employers and mining engineers, not on doctors and sociologists. There can be no speedy amelioration without the vital co-operation of the men themselves and their unions. This constitutes a challenge to discipline and leadership.

There are several important prerequisites which must be fulfilled. First, the whole problem must be extracted from 'politics'; secondly, it must be realized that pneumoconiosis of coal-miners is not peculiar to South Wales; thirdly, the fine focus on disease and compensation must give way to the acceptance that existent knowledge of the causation of the disease is already adequate, without further research, to enable effective prevention. Mining engineers in South Wales, by such methods as water infusion, have already made a useful start. The clamant demand is for more coal-higher and greater 
production. To this end mechanization and more mechanization and more men to work the machine is the invariable answer. Is it quite certain that in some mines more coal-cutters and longer conveyorbelts are not indirectly diminishing output by the deleterious effects on the men ? It has almost become trite among doctors to say this is an engineering problem. Until the disease is controlled so as not to abridge life or seriously impair health in a normal working span, then the medical man must bear his full part in the team. But in this particular field the medical man is simply an expert adviser; he is not the director in charge of operations. Though the production of dust must be kept to a minimum, considerable dust is unavoidable, and the occurrence and, in certain circumstances, the progression of the disease reflects the extent of the dangerous concentrations of air-borne dust. The medical man has two main duties : first, to assist the engineers to locate the dangerous operations and stations, and secondly, to supervise the health of affected men still at work.

The final speaker, Sir Andrew Bryan (National Coal Board, London), speaking on "Accidents in Coal Mines", said that of all the major industries in Great Britain, coal-mining is the most hazardous. Employing less than one-twentieth of the working population, it accounts for nearly one-quarter of all industrial accidents. The reasons for this high accident-rate lie in the nature of the work of the miner and in the vital differences between his working environment and that of other industrial workers. Mining is for the most part a continual striving against great natural hazards in confined and poorly illuminated spaces.

Up to the present time the attack upon the accident problem has been mainly by statutory regulation and inspection, assisted by scientific research into specific mining dangers and a raising of the standards of education and training of miners; and, more directly, by improvements in standards of housing, welfare and recreational facilities for the mining community as a whole. That these lines of attack have achieved a considerable measure of success over the years is shown by the progressive reduction in the accidentrates for fatal and serious non-fatal accidents. There is still much to be done along these lines. The attack must continue by way of further regulations as the results of new mining methods, machines and safety practices are devised; by way of higher standards of education or training for mine managers, officials and workmen; by the general adoption of higher standards of engineering production; and by the expansion of social and welfare activities in all mining communities. But new methods are needed if the progress of accident reduction is to be accelerated ; and for this purpose new methods of investigation are required.

As examples of new lines of approach, the relationship between accident-rate, absenteeism and size of pit has been considered. There is a close correlation with the size of pit and the accident-rate per 100,000 man-shifts. In pits employing less than fifty miners the rate is $63 \cdot 5$, but rises to $166 \cdot 6$ in pits with more than three thousand. The reasons for this require study. Further, it can be shown that a high accidentrate can be correlated with a high pneumoconiosisrate. Researches into observable features of human behaviour such as accident-rates, and their relation to the size of the groups in which men work, may, in the final result, throw light upon the structure of authority in the pit and the extent to which the men feel themselves to be part of the organization in which they are employed. Coal must always be got by small groups of men working in isolation and under remote supervision. The attitudes of these groups and the extent to which they each identify themselves with the pit as a whole are problems needing urgent investigation that confront the industry.

\section{SENSES AND BEHAVIOUR OF ANIMALS}

$\mathrm{O}^{\mathrm{N}}$ August 13 at Edinburgh the second joint session of Sections D (Zoology) and J (Psychology) of the British Association (the first was at Aberdeen in 1934) was held under the chairmanship of Dr. C. F. A. Pantin, the subject being the "Senses and Behaviour of Animals".

Prof. R. J. Pumphrey (University of Liverpool) spoke of the coming of age of 'ethology', a word recently applied to the study of the behaviour of all animals including man. Ethology, in this wide sense, evidently stems from the "Origin of Species" (1859) and the "Expression of the Fmotions in Man and Animals" (1872); but its development has been arrested until very recently. This arrest is traceable to the influence of Descartes. In spite of the intellectual acceptance of evolution as a fact of history, a conscious or sub-conscious reservation in favour of dualism led to the persistent separation of a human ethology (psychology) which was rootless and arid, from an animal ethology, which carried the worship of the Golden Calf of objectivity to ludicrous lengths. The many 'languages of objective description' that have been applied to animal behaviour are seen in retrospect to cloak a belief in a physico-chemical etiology of behaviour, and an equation of meaning with statistical significance.

Prof. Pumphrey concluded that the time is now ripe for an integrated ethology with a common language and a common aim. A re-examination of the basic principles of semantics is needed, for semantics is doubly involved in ethology, both in the technique and in the description and interpretation of results.

The next speaker, Prof. J. E. Harris (University of Bristol), pointed out that a physiological and 'mechanistic' treatment is still appropriate to the genesis of behaviour patterns in the embryo. He showed in detail how this genesis can be related to the development of the muscular and nervous systems of young fish and amphibians, and how the first myogenic movements and rhythms are modified as motor and sensory nerve cells, and connexions and tracts become functional until the swimming rhythm is perfected.

Prof. R. W. Russell (University College, London) said that he was a psychologist and necessarily approached animal ethology with the terminology and point of view of human psychology. Nevertheless, he agreed with Prof. Pumphrey about the importance of semanties and the desirability of an integrated ethology with a common language. Such meetings as the present joint discussion and the Cambridge symposium on behaviour two years earlier reflect the desire of psychologists and animal ethologists alike to understand each other and to contribute jointly to an understanding of behaviour.

Prof. Russell then described the extensive field of animal psychopathology which has been explored 